\title{
Modos de Fazer da Inclusão um Imperativo Educacional
}

\author{
Rodrigues Martieli de Souza \\ Universidade Federal de Santa Maria (UFSM)- Santa Maria- Rio Grande Do Sul- Brasil \\ martielisr@gmail.com
}

Possa Leandra Boer

Universidade Federal de Santa Maria (UFSM)

leandrabp@gmail.com

\section{Resumo}

O artigo procura problematizar produção de discursos sobre práticas de inclusão, de certa forma naturalizadas, na escrita de expertises publicada e divulgada numa coletânea de textos intitulada Tornar a Educação Inclusiva, organizado por Fávero, Ferreira, Ireland e Barreiros (2009). Coletânea publicada na parceria entre a Organização das Nações Unidas para a Educação, a Ciência e a Cultura (UNESCO) e a Associação Nacional de Pós-Graduação e Pesquisa em Educação (ANPEd). Tomamos esta coletânea como material de análise por entender que o papel das expertises, dos organismos internacionais como UNESCO e de associações de impacto acadêmico na produção de relações de saber-poder como é o caso da ANPEd no Brasil, assumem uma posição de invenção de práticas operadas por determinados imperativos governam/orientam o espaço escolar e os sujeitos na contemporaneidade. Metodologicamente buscou-se pensar diferentes relações sobre a inclusão, pois nosso objetivo não é encontrar a verdadeira inclusão, mas tensionar práticas discursivas no sentido de percebê-las pensando e produzindo uma realidade e sujeitos. Esta coletânea de artigos científicos promete promover o aprofundamento e o debate sobre as práticas da educação inclusiva, modos de fazer a inclusão chanceladas e legitimadas tanto pela UNESCO como pelos expertises brasileiros ligados a ANPEd. A problematização foi modesta, mas buscamos fazer uso da noção de governamentalidade (a partir dos estudos foucaultianos) para fazer ver os modos de funcionamento e os sujeitos que são convocados a produzirem tais práticas.

\section{Abstract}

The article seeks to problematize the production of discourses about inclusion practices, in a certain way naturalized, in the writing of expertises published and published in a collection of texts entitled Making Inclusive Education, organized by Fávero, Ferreira, Ireland and Barreiros (2009). Collection published in the partnership between the United Nations Educational, Scientific and Cultural Organization (UNESCO) and the National Association of Postgraduate and Research in Education (ANPEd). We take this collection as an analysis material because it understands that the role of expertises, international organizations such as UNESCO and associations of academic impact in the production of knowledge-power relations such as ANPEd in Brazil, assume a position of invention of practices operated by certain imperatives govern / guide the school space and the subjects in the contemporaneity. Methodologically we tried to think about different relations about inclusion, because our objective is not to find true inclusion, but to stress discursive practices in the sense of perceiving them thinking and producing a reality and subjects. This collection of scientific articles promises to promote the deepening and debate on the practices of inclusive education, ways of making the inclusion chanceladas and legitimized by UNESCO as well as the Brazilian expertises linked to ANPEd. The problematization was modest, but we sought to make use of the notion of governmentalality (from the Foucaultian studies) to show the modes of functioning and the subjects that are called to produce such practices.

Palabras clave: Produção de Discurso; governamentalidade; inclusão.

Keywords: Discourse Production; governmentality; inclusión. 


\section{Contexto da discussão}

A análise da coletânea de textos Tornar a Educação Inclusiva, organizado por Fávero, Ferreira, Ireland e Barreiros (2009), escritos por expertises (aqueles que são autorizados a proferirem a verdade, que ocupam o lugar na ordem do discurso e que cumprem com determinadas regras (FOUCAULT, 2006) e legitimada por um organismo internacional como a UNESCO e por uma Associação de Pesquisa, como a ANPEd no Brasil, assume a possibilidade de nos emprenharmos na hipercrítica, tendo em vista que, a própria analise é feita de uma prática discursiva na condução de condutas em torno do tema inclusão, inclusão educacional e produção de sujeitos inclusivos para uma sociedade do presente.

Requer compreender a produção do saber e da relação de forças que tem a palavra inclusão como meio de produção da verdade e dos modos de se conduzir e, por isso a análise é uma possibilidade crítica que 'puxa seu próprio tapete', pois problematiza o que ela produz como entendimento da realidade e coloca aquilo que diz representar como a própria produção da realidade (POSSA, 2013).

Por isso, não perseguimos o mérito da análise da totalidade, mas de rastros possíveis. Buscamos "nos amarrar às superfícies" (VEIGA-NETO, 2007, p. 33) do discurso ordenado e colocado em funcionamento sobre inclusão, nessa coletânea, já que a inclusão educacional é tomada como "[...] o maior desafio do sistema escolar em todo o mundo" (AINSCOW, 2009, p. 11).

Essas produções no espaço científico, trazidas e compartilhadas dão suporte para como se pensa e se produz a realidade, bem como os sujeitos que a habitam. A materialidade analítica construída para essa problematização, a partir da produção de discursos sobre as práticas de inclusão educacional nos apontam para a naturalização do imperativo inclusivo como desafio e tida inquestionável. No entanto, cabe uma pergunta problematizadora: A partir de que possíveis naturalizações, a inclusão passa a fazer parte das práticas educativas e da produção de tipos específicos de sujeitos? Como os modos de dizer dos expertises, legitimados pela UNESCO e por esta associação de pesquisa contribuem para a produção da inclusão como verdade deste tempo?

Para trazer elementos para essas problematizações, sem a pretensão de esgotá-las mas, circundá-las pelas superfícies dos textos da Coletânea, construímos uma materialidade analítica que se produziu a partir dos seguintes focos de análise: conceito de inclusão presente nos diversos textos; entendimento de práticas de educação inclusiva; a descrição de a quem se destina a educação inclusiva e, assim, os sujeitos incluídos como uma nova categoria de sujeitos das práticas educacionais; e, por fim, a apresentação dos sujeitos inclusivos como característica daqueles que se responsabilizam pelos processos de inclusão.

Um primeiro momento, já na apresentação da coletânea, encontramos que "A presente coletânea sobre educação inclusiva, congregando um conjunto de ensaios sobre a temática, de autoria de estudiosos da área, vem preencher uma lacuna neste campo de investigação" (Aguiar, 2009, p. 09). Observa-se que as lacunas só podem ser preenchidas por estudiosos e autores que sejam capazes de dizer e fazer, produzir uma realidade, a qual pode ser descrita como desafiadora e que, por isso, legitimada como mais verdadeiro em relação a outros modos.

Modos de dizer a verdade que são legitimados pela ANPEd e a UNESCO, esta organização e associação que "têm plena convicção da relevante contribuição que os trabalhos nela [coletânea] reunidos trazem" (Aguiar, 2009, p. 09). A plena convicção é uma afirmativa que só pode ser tomada como verdadeira porque é assumida numa rede institucional reconhecida, que se antecipa que se impõe através de um sujeito consciente (os expertises) capaz de ver e verificar e de prescrever a partir de um nível técnico. Ou seja, a naturalização da inclusão como algo que esteve desde sempre aí, nos parece ser apresentada como "[...] uma verdade que seria riqueza, fecundidade, força doce e insidiosamente universal" (FOUCAULT, 2006, p. 20).

Apresentada a coletânea, passamos a identificação dos textos apresentados na tabela abaixo: 


\begin{tabular}{|c|c|c|}
\hline AUTORIA & TÍTULO & RESUMO SÍNTESE \\
\hline $\begin{array}{c}\text { AINSCOW, } \\
\text { Mel, } \\
\text { p. 11-23. }\end{array}$ & $\begin{array}{l}\text { Tornar a Educação } \\
\text { Inclusiva: Como esta } \\
\text { tarefa deve ser } \\
\text { conceituada? }\end{array}$ & $\begin{array}{l}\text { Aponta a educação inclusiva como direito de todos, para receber } \\
\text { educação de qualidade capaz de satisfazer necessidades básicas } \\
\text { de aprendizagens e enriquecer a vida das pessoas. Discute o } \\
\text { desenvolvimento da Educação Especial (segregação, integração e } \\
\text { inclusão) e o esforço mundial pós Declaração de Salamanca (1994), } \\
\text { incitada na Conferência de Educação Para Todos (1990) e reiterada } \\
\text { pela conferência de Dakar (2000) para a inclusão educacional. } \\
\text { Também, busca definir a inclusão apontando o seu uso num } \\
\text { contexto mais amplo: as exclusões disciplinares e de vulneráveis, } \\
\text { no entanto, alerta para a discussão especificidades referentes as } \\
\text { deficiências e necessidades de Educação Especial. Por fim, conclui } \\
\text { que o "desenvolvimento da inclusão, [...] nos envolve [a todos] na } \\
\text { tarefa de tornar explícitos os valores que servem de base para } \\
\text { nossas ações, práticas e políticas, e para a nossa aprendizagem } \\
\text { sobre como melhor relacionar as nossas ações a valores inclusivos" } \\
\text { (AINSCOW, 2009, p. 19). }\end{array}$ \\
\hline $\begin{array}{l}\text { FERREIRA, } \\
\text { Windzy, } \\
\text { p 25-56. }\end{array}$ & $\begin{array}{c}\text { Entendendo a } \\
\text { discriminação contra } \\
\text { estudantes com } \\
\text { deficiência na escola. }\end{array}$ & $\begin{array}{l}\text { Aborda a importância da inclusão como tema na formação de } \\
\text { professores e justifica isso com uma reflexão sobre as experiências } \\
\text { de discriminação contra estudantes com deficiências nas escolas, } \\
\text { se constituem como elemento comum na vida daqueles que } \\
\text { pertencem a grupos vulneráveis. Reforça a ideia de um público } \\
\text { a ser incluído identificando que "As pessoas que nascem com } \\
\text { deficiências ou as adquirem ao longo da vida são continuamente } \\
\text { privadas de oportunidades de convivência com a família e seus } \\
\text { pares, de aprendizagem educacional formal (na escola) e informal } \\
\text { (em casa, na rua etc.), de possibilidades de acesso ao trabalho e } \\
\text { a atividades de lazer e cultura, entre outros" (FERREIRA, 2009, p. } \\
26 \text { ). Ainda, enfatiza o desprepara da escola e dos professores para } \\
\text { o atendimento das necessidades educativas dos estudantes com } \\
\text { deficiência e conclui considerando a necessidade de mudanças } \\
\text { das práticas educacionais e de perspectiva da escola apontando } \\
\text { a "conscientização da comunidade escolar e o seu envolvimento } \\
\text { como um todo no processo de construção da cultura inclusiva" } \\
\text { (FERREIRA, 2009, p. 50). }\end{array}$ \\
\hline $\begin{array}{l}\text { FERREIRA, } \\
\text { Júlio Romero, } \\
\text { p. } 55-64 .\end{array}$ & $\begin{array}{l}\text { Financiamento da } \\
\text { educação básica: } \\
\text { o público e o } \\
\text { privado na educação } \\
\text { especial brasileira. }\end{array}$ & $\begin{array}{l}\text { A intenção do texto de Ferreira, é localizar a educação especial no } \\
\text { financiamento da Educação Básica Brasileira, discutindo modos de } \\
\text { terceirização do financiamento educacional da Educação Especial, } \\
\text { por parte do Estado, para as instituições filantrópicas. Denuncia que } \\
\text { na história da educação brasileira muito pouco o Estado se preocupou } \\
\text { com a educação das pessoas com deficiência e como a Educação } \\
\text { Especial se constitui, ao longo desta história, como um subsistema } \\
\text { paralelo. Mostra que o financiamento da Educação Especial foi tema } \\
\text { de debate na partir da LDB de } 1996 \text { e no PNE (2001) e comprova } \\
\text { com dados estatísticos o pouco impacto destas discussões no } \\
\text { real financiamento, tendo em vista um maior controle estatístico } \\
\text { e ampliação de matrículas de estudantes com deficiência nas } \\
\text { instituições de ensino. Conclui afirmando que mais que discutir apoios } \\
\text { especializados para estudantes com necessidades educa cionais } \\
\text { especiais é que o Estado assuma o financiamento de uma escola } \\
\text { pública, democrática e de qualidade, pois não basta responsabilizar a } \\
\text { Educação Especial e a sensibilidade dos docentes. }\end{array}$ \\
\hline
\end{tabular}




\begin{tabular}{|c|c|c|}
\hline $\begin{array}{l}\text { FLEURI, } \\
\text { Reinaldo Matias, } \\
\text { p. } 65-88 .\end{array}$ & $\begin{array}{c}\text { Complexidade e } \\
\text { interculturalidade: } \\
\text { desafios emergentes } \\
\text { para a formação } \\
\text { de educadores em } \\
\text { processos inclusivos. }\end{array}$ & $\begin{array}{l}\text { O texto analisa trabalhos apresentados no GT Educação Especial } \\
\text { da ANPEd no ano de } 2005 \text { que tinham como temáticas a formação } \\
\text { de professores para a educação inclusiva mostrando como esses } \\
\text { se articulam a uma ampla discussão nacional e internacional. Trata, } \\
\text { ainda do texto das definições sobre deficiências e necessidades } \\
\text { especiais do abandono nas definições políticas de práticas de } \\
\text { segregação e de integração e valoriza a possibilidade de práticas } \\
\text { inclusivas em que os estudantes não precisem se ajustar aos padrões } \\
\text { de normalidade, pois é a escola que precisa se reestruturar para dar } \\
\text { conta da diversidade. Conclui, afirmando que "o educador terá a } \\
\text { tarefa de prever e preparar recursos capazes de ativar a elaboração } \\
\text { e a circulação de informações entre sujeitos, de modo que se } \\
\text { reconheçam e se auto organizem em relação de reciprocidade entre } \\
\text { si e com o próprio ambiente sociocultural" (FLEURI, 2009, p. 85). }\end{array}$ \\
\hline $\begin{array}{l}\text { SÁNCHEZ, } \\
\text { Pilar Arnaiz, } \\
\text { p. 89-103. }\end{array}$ & $\begin{array}{l}\text { A educação inclusiva } \\
\text { na Espanha. }\end{array}$ & $\begin{array}{l}\text { Este trabalho apresenta uma série de propostas que estão sendo } \\
\text { aplicadas na Espanha, o que tem um valor primordial para entender } \\
\text { a universalização da inclusão como um modelo universal que, aju- } \\
\text { dará as escolas a realizar o processo de transformação de que ne- } \\
\text { cessitam para serem mais inclusivas. Apresenta a possibilidade de } \\
\text { progresso da escola tomando como referência as noçães paradig- } \\
\text { máticas da segregação, integração e inclusão e conclui que a filo- } \\
\text { sofia da inclusão é um bom caminho para "mudar as organizações } \\
\text { das escolas, a utilização e a distribuição tanto dos recursos pes- } \\
\text { soais como dos materiais, que geralmente estão organizados para } \\
\text { manter o próprio status quo, em vez de apoiarem novas formas de } \\
\text { desenvolvimento profissional" (SÁNCHEZ, 2009, p. 100). }\end{array}$ \\
\hline $\begin{array}{l}\text { COSTA, } \\
\text { Ana Maria, } \\
\text { p. 105-119. }\end{array}$ & $\begin{array}{l}\text { Currículo funcional } \\
\text { no contexto da } \\
\text { educação inclusiva. }\end{array}$ & $\begin{array}{l}\text { O texto discute programas de educação especial para crianças } \\
\text { e jovens com deficieincia intelectual e foca as estratégias } \\
\text { preconizadas por Lou Brown tendo em vista: "a) a publicação da lei } \\
\text { norte- americana PL.94/142; b) os desenvolvimentos de estratégias } \\
\text { comportamentalistas; c) a introdução de programas de educação } \\
\text { precoce e, de um modo geral, d) o progresso nos domínios da } \\
\text { avaliação e da intervenção educativa especializada" (COSTA, 2009, } \\
\text { p. 105). Apresenta com conceitos, objetivos e modos de fazer, aos } \\
\text { educadores brasileiros, uma abordagem que tem revelado enorme } \\
\text { eficácia na inclusão educativa, social e profissional das pessoas } \\
\text { com deficiência intelectual acentuada, sendo esta, "potencial de } \\
\text { transformação e de progresso" (COSTA, 2009, p. 117). }\end{array}$ \\
\hline $\begin{array}{l}\text { AMARAL, } \\
\text { Tatiana Platzer do, } \\
\text { p. } 121-140 .\end{array}$ & $\begin{array}{l}\text { O Processo de } \\
\text { escolarização e } \\
\text { a produção de } \\
\text { subjetividade na } \\
\text { condição de aluno } \\
\text { com deficiência } \\
\text { mental leve. }\end{array}$ & $\begin{array}{l}\text { Este artigo analisa e discute o processo de subjetivação a que são } \\
\text { submetidos, alunos que frequentam o ensino especial, à condição de } \\
\text { pessoa com deficiência intelectual leve. A partir de estudos de caso } \\
\text { registra a exclusão como fracasso escolar e, por isso a necessidade } \\
\text { de a inclusão escolar levar em conta o contexto histórico e cultural } \\
\text { dos indivíduos. Conclui considerando a necessidade na sociedade } \\
\text { e grupos sociais referendarem para a inclusão o acolhimento e o } \\
\text { reconhecimento do direito de participação dos deficientes mentais. }\end{array}$ \\
\hline
\end{tabular}




\begin{tabular}{|c|c|c|}
\hline $\begin{array}{c}\text { MAFFEZOL, Roberta } \\
\text { Roncali; GÓES, Maria } \\
\text { Cecília Rafael de, } \\
\text { p 141-157. }\end{array}$ & $\begin{array}{l}\text { Jovens e adultos com } \\
\text { deficiência mental: } \\
\text { seus dizeres sobre } \\
\text { o cenário cotidiano } \\
\text { de suas relações } \\
\text { pessoais e atividades. }\end{array}$ & $\begin{array}{l}\text { O texto intui que a Educação Especial como campo de ação com } \\
\text { deficiência se constitui num fundamento para a patologização do } \\
\text { sujeito, tendo em vista modos de atuação que levam em conta a } \\
\text { 'anormalidade. Alerta para modelos sociais da anormalidade e por } \\
\text { isso da instituição da falta para a compreensão do funcionamento } \\
\text { de jovens e adultos deficientes mentais que tendem a mostrar } \\
\text { poucas capacidades e um padrão infantilizado de conduta. O estudo } \\
\text { de campo realizado teve como propósito analisar, nos dizeres } \\
\text { de pessoas com deficiência mental, os modos pelos quais elas } \\
\text { reconhecem e significam sua inserção nos espaços do cotidiano. }\end{array}$ \\
\hline $\begin{array}{l}\text { LACERDA, Cristina } \\
\text { B. F. de; POLETTI, } \\
\text { Juliana Esteves, } \\
\text { p. 159-175. }\end{array}$ & $\begin{array}{l}\text { A escola inclusiva } \\
\text { para surdos: a } \\
\text { situação singular do } \\
\text { intérprete de } \\
\text { língua de sinais. }\end{array}$ & $\begin{array}{l}\text { O texto especifica a educação de surdos e a inclusão do personagem } \\
\text { interprete de língua de sinais no contexto educacional. Enfoca } \\
\text { problemas e limitações na atuação do intérprete educacional e } \\
\text { a necessidade de ampliação das pesquisas na área. A partir de } \\
\text { entrevistas com interpretes estabelece uma discussão da relação } \\
\text { entre este e os professores, sobre seu papel na organização e } \\
\text { práticas pedagógicas inclusivas, de sua relação com os alunos } \\
\text { surdos e conclui que no processo de inclusão de alunos surdos o } \\
\text { intérprete também faz parte do cenário do ensino e da aprendizagem. }\end{array}$ \\
\hline $\begin{array}{l}\text { SILVA, Luzia Guacira, } \\
\text { p. } 177-198 .\end{array}$ & $\begin{array}{l}\text { Múltiplas } \\
\text { representações de } \\
\text { docentes acerca } \\
\text { da inclusão de } \\
\text { aluno cego. }\end{array}$ & $\begin{array}{l}\text { O texto traça a busca do desenvolvimento de açães que visam a } \\
\text { inclusão pessoas cegas nos sistemas regulares de ensino. Diante } \\
\text { do estudo a autora busca entender a natureza da aprendizagem } \\
\text { de alunos cegos bem como, as estratégias de ensino utilizadas } \\
\text { com um esse púbico em classe regular e como são estabelecidas } \\
\text { as relações interpessoais entre o aluno cego, seus professores e } \\
\text { colegas de classe, percebendo até que ponto a inclusão escolar } \\
\text { permite ou facilita o desenvolvimento e a aprendizagem de alunos } \\
\text { cegos. Conclui que ações educacionais sugeridas ao longo do } \\
\text { texto podem contribuir "[...] para a inclusão social desses alunos, } \\
\text { preparando-os para enfrentar os desafios de uma sociedade que } \\
\text { vem sendo convidada a rever paradigmas e a conviver com as } \\
\text { diferenças (SILVA, 2009, p. 196). }\end{array}$ \\
\hline $\begin{array}{l}\text { FLEITH, } \\
\text { Denise de Souza, } \\
\text { p. } 199 .\end{array}$ & $\begin{array}{l}\text { Mitos e fatos } \\
\text { sobre os } \\
\text { superdotados. }\end{array}$ & $\begin{array}{l}\text { No ensejo de abarcar a deficiência ou um certo público da inclusão } \\
\text { educacional no campo da Educação especial este texto vai abordar } \\
\text { mitos e fatos em torno daqueles classificados como superdotados } \\
\text { ou altas habilidades. Então a discussão busca desmistificar } \\
\text { conceitos de senso comum de professores e comunidade em geral } \\
\text { e a necessidade de que as propostas educacionais inclusivas } \\
\text { promovam um ambiente adequado para o desenvolvimento das } \\
\text { habilidades e para o ajustamento emocional e social. Na esteira } \\
\text { entre um modelo de segregação e outro de inclusão aponta para } \\
\text { modos de avaliação do aluno com altas habilidades/superdotado } \\
\text { e enuncia a necessidade de formação de professores a inclusão } \\
\text { destes alunos. }\end{array}$ \\
\hline
\end{tabular}

Fonte: Elaborada pelas as autoras 
Tendo apresentado uma síntese dos textos nos resta identificar que usos de noções analíticas vamos utilizar a partir de agora, e neste sentido anunciamos, capturadas pelos estudos foucaultianos, a noção de governamentalidade, no sentido de fazer ver alguns efeitos de produção que as práticas discursivas sobre inclusão, práticas de inclusão educacional podem estar produzindo nos sujeitos que estão envolvidos por elas.

Antes de adentramos na análise, consideramos apresentar o que dá noção de governamentalidade nos interessa neste momento. A noção foucaultiana de governamentalidade é tomada como um "[...] conjunto das práticas pelas quais é possível constituir, definir, organizar, instrumentalizar as estratégias que os indivíduos, em sua liberdade podem ter uns em relação aos outros" (FOUCAULT, 2006, p. 286).

Estes conjuntos de práticas são entendidas como incidindo nos indivíduos a partir das relações que eles estabelecem com outros e, neste caso, relações que são produtoras dos e produzidas pelos/as expertises de um campo de saber. Um conjunto de práticas discursivas que atuam como um modo de condução de condutas; um tipo de condução por captura pela verdade denominada por inclusão e práticas de inclusão. Para Foucault (1995), "[...] este conjunto de práticas é uma combinação tão astuciosa das técnicas de individualização e dos procedimentos de totalização" (p. 236).

Com isso, adentramos à análise específica e tangencial (porque não fazemos opção nem pela totalidade e nem pela profundidade) dos textos buscando apresentar alguns elementos em que as práticas de inclusão, que estão tão fortemente dirigidas nos discursos dos expertises, tem por efeito, a produção de individualização (os deficientes, os marginalizados, os vulneráveis e segregados) e, conseguinte efeito de totalização na condução de condutas tanto dos que se pretende incluir como daqueles que precisam se responsabilizar por serem inclusivos.

\section{Discussão... Entre conceito, praticas educativas inclusivas e produção de sujeitos}

$\mathrm{Na}$ análise desta subseção buscamos mostrar que nos textos da coletânea a perspectiva inclusiva tem operado certa gestão totalizadora e naturalizada de um conceito para a inclusão escolar. Este tem por efeito dinamizar as práticas educacionais que qualificadas pela política educacional, os modos de atuação dos sistemas educacionais e instituições escolares. Mais que isso, esta perspectiva inclusiva tem acionado a constituição objetiva da escola e de subjetividades docentes e discentes.

Observa-se que a inclusão é denominada por uma "[...] crença de que a educação é um direito humano básico e o fundamento para uma sociedade mais justa" (Ainscow, 2009, p.11). Uma ideia que tende a ser determinada por um conjunto de valores apontados histórica, social e culturalmente como necessidades básicas e dentre elas estar dentro da instituição, regulada que é responsável por padronizar habilidades, conhecimentos e competências necessárias para o desenvolvimento da sociedade, para ser produtivo e produzir no contexto desta sociedade.

Nessa lógica, a inclusão como crença de uma sociedade justa impõe-se uma perspectiva de aprendizagens justas que interditam outras formas de aprender e de constituir conhecimentos. Ou seja, a inclusão como imperativo até a pouco debatida e questionada na escola e no sistema educacional, torna-se aceitável e tecnicamente útil tendo em vista a rede de saberes e de poder autorizados por uma política regulatória dos padrões de condutas que atinge a todos e a cada um, pois a educação é direito de todos, precisa atingir a todos e a cada um.

Ainda, como crença no direito humano e no justo, as instituições escolares, que por efeito precisam se constituir inclusivas, se veem na obrigação legal e moral, de aceitar e colocar a todos e a cada um, por meio da matrícula no interior da instituição, porque o efeito projetado pela "inclusão social, a escolar em particular constitui uma tarefa complexa, porém não impossível” (SILVA, 2009, p.186).

Assim, a inclusão como uma das palavras mais utilizadas na atualidade que adjetiva política e a legislação educacionais, as instituições e as atividades educativas, também, tem adjetivado o comportamento, ações e atuações de professores, agentes educativos e estudantes. A inclusão é mais que uma simples palavra que qualifica, pois quando a identificamos nos jogos de linguagem podemos entendê-la como "práticas, atividades, ações e reações" (HACKER, 2000, p. 13). 
Inclusão que disputada nas relações de poder, sutilmente se expandem para além das tradicionais e dicotômicas relações dominantes e dominados, incluídos e excluídos, pois estabelece que, para o desenvolvimento social, econômico e de mercado é necessário que todos estejam incluídos. Sob isso encontramos em um dos textos da coletânea:

[...] articulação ampla de valores com os quais nos identificamos e nos comprometemos, e de práticas inclusivas que acreditávamos serem importantes de se tentar incorporar nas escolas. (...) envolve na tarefa de tornar explícitos os valores que servem de base para nossas ações, práticas e políticas, e para a nossa aprendizagem sobre como melhor relacionar as nossas ações a valores inclusivos (AINSCOW, 2009, p. 19).

Os valores inclusivos apresentados nos textos, a seguir, referem-se "à igualdade, à participação, à comunidade, à compaixão, ao respeito pela diversidade, à sustentabilidade e ao direito" (AINSCOW, 2009) e, ainda "como um processo de transformação de valores em ação, resultando em práticas e serviços educacionais, em sistemas e estruturas que incorporam tais valores" (Idem, p. 21).

Valores em ação que implicam na inclusão como alicerces para a gestão e geração de capital humano, pois se parte da população estiver em condições de exclusão, esta coloca em risco a nação e sua economia na globalização dos mercados, do comércio, dos investimentos, da produção e do consumo. Neste sentido, a inclusão se utiliza de outro conjunto de palavras: protagonismo, autonomia, liberdade, eficiência, novas competências, comprometimento, diagnóstico, correção, responsabilização.

Sobretudo, adjetiva a educação, educação para todos, reforçando a narrativa dos direitos humanos numa sociedade do conhecimento que precisa de seres humanos em aprendizagem ao longo da vida. Num mundo que, em perspectiva global, tem sido gestado com base em processos de aquisição do conhecimento tomando indicadores de desempenho de sistemas, instituições e práticas educativas, como referência para consolidação do desenvolvimento social e econômico, na denominada sociedade da aprendizagem.

A inclusão abrange...

[...] todas as crianças e jovens nas escolas; está focada na presença, na participação e na realização; inclusão e exclusão estão vinculadas, de maneira que a inclusão envolve o combate ativo à exclusão; a inclusão é vista como um processo sem fim. Assim, uma escola inclusiva é aquela que está evoluindo, e não aquela que já atingiu um estado perfeito (AINSCOW, 2009, p. 20).

O estado de perfeição evolutivo e progressivo é expressado ao longo dos textos da coletânea representa a inclusão como uma estratégia de governo antônima da exclusão, a como nos fragmentos abaixo retirados dos textos da coletânea:

[...] de eliminar a exclusão social que resulta de atitudes e respostas à diversidade com relação à etnia, idade, classe social, religião, gênero e habilidades. [...] educação não pode representar mais um mecanismo para excluir as pessoas cujas necessidades de aprendizagem exigem uma atenção especial" (DEFOURNY, 2009, p. 01, grifos nossos).

[...]são duas exclusões associadas: a questão do não acesso e o problema da segregação, com a desnecessária manutenção de alunos nas escolas especiais. (FERREIRA, 2009, p.60).

A educação especial foi oferecida, por vezes, como complemento à educação geral [...] totalmente segregada. [...] assumia a forma de escolas especiais separadas das escolas regulares[...]. "A integração de crianças com deficiências nas escolas regulares envolveu, em alguns casos, a "transplantação" de práticas especiais de educação para o ambiente escolar comum" (MEIJER; PIJL; HEGARTY, 1997). A inclusão como modelo de progresso [...]. Este pensamento revisado sugere que o progresso será mais provável se reconhecermos que as dificuldades vividas por estudantes resultam das formas com que as escolas estão organizadas atualmente e dos métodos de ensino que são oferecidos. (AINSCOW, 2009, p. 14). 
Na narrativa da inclusão há caracterização de um público de estudantes com deficiência constituindo sujeitos a serem incluídos, se constitui a ideia de evolução e progresso. A inclusão, antônimo da exclusão, se configura nos discursos das expertises como princípio orientador das atuais práticas em educação. É o ponto cronológico do presente que permite revisitar, desvelar e entender o passado das práticas de educação e de educação especial, estas que possibilitariam reconhecer a inclusão, a melhor prática, o melhor modo de conduzir as relações sociais e educacionais em relação à pessoa com deficiência e a outras formas de diversidades de alunos dentro de um contexto social que segrega e marginaliza historicamente.

A inclusão que como prática educacional assume um papel de ordenação capaz de reunir num espaço comum e homogêneo saberes sobre a deficiência e dá a diversidade, num contexto social e político em que, todos indivíduos passam a ter o direito e o dever de frequentar o espaço educativo escolar. Condição que gera o motivo para produzir sujeitos dispostos a se responsabilizar e lutar pela inclusão, que nomeiam, falam e pensam a deficiência nas instituições e práticas educacionais.

A possibilidade de produção do sujeito que se responsabiliza pela inclusão de outros, governa sua conduta para ser inclusivo e ao mesmo tempo que opera saberes capazes de dizer quem é o sujeito a ser incluído, não está fora de um campo de saber e de práticas de ordenação dos modos de saber e, por conseguinte, de normatização dos modos de ser que se constituem o objeto da inclusão no espaço educacional.

Por isso, a inclusão apresentada nesta coletânea está na ordem de um poder individualizante que disciplina o corpo e o indivíduo e um poder totalizante que controla a circulação das pessoas e gerencia o risco no sentido de identificar que podem ser normalizados socialmente e educacionalmente a partir da ação planejada das práticas educativas.

\section{Considerações finais}

A Educação Inclusiva diz respeito à educação e aos processos de escolarização organizados a partir do princípio de mobilidades e de produção de sujeitos (MENEZES, 2011). Esses sujeitos desejam permanecer e estar na posição de sujeitos que estão incluídos. Lopes e Veiga-Neto (2007) indicam que as políticas de inclusão, realizam-se no momento em que normais e anormais são colocados juntos, num mesmo espaço/tempo. As práticas de inclusão escolar, por sua vez, atuam nesse estar junto com a intenção de manter os alunos nas escolas e, inscrever nos seus comportamentos, nas suas aprendizagens o desejo de ser e a possibilidade de permanecer incluído. Ainda, segundo Possa (2013) estas práticas de inclusão capturam a totalidade para que sejam justos e por isso responsáveis para que a inclusão se torne verdadeira.

Nos fragmentos abaixo,

[...] sujeitos socioculturais apresentam-se como sujeitos coletivos que buscam interagir e dialogar com outros sujeitos, lutando por construir condições de equidade de oportunidades e de direitos, para se reconhecerem em suas diferenças. (FLEURI, 2009, p. 68).

Todos os alunos se beneficiam se as escolas centralizarem seu interesse em desenvolver estratégias de apoio para eles, ou seja, em proporcionar uma educação que responda às diferenças individuais de cada membro da escola (SÁNCHEZ,2009, p.91).

Esses textos permitiram ver os diferentes modos de atuação da educação inclusiva em ação e a centralidade da educação na difusão dos saberes e sua disseminação como uma verdade incontestável. O modo como esses expertises olharam para esses discursos na constituição das práticas educativas, mostrou como a inclusão "aciona saberes, constitui processos de subjetivação, constrói subjetividades e refina estratégias [...] que atendam a tal configuração" (MACHADO, 2016, p. 75).

Por fim, ao longo desta escrita, nossa intenção foi mostrar os discursos, produzidos pelas expertises na área da educação, enquanto uso e produção das práticas de inclusão. Essa noção de discurso nos condiciona a produções, para se fazer ver os modos de funcionamento e os sujeitos que são convocados para tais práticas. Também é possível verificar que alguns discursos colocam 
no jogo o professor como centro das práticas de inclusão, reforçam as práticas discursivas que poderiam tornar possível políticas e processos de inclusão em que se naturalizam compromissos de todos com a inclusão.

A coletânea Tornar a educação inclusiva (2009), resultado da parceria entre a UNESCO e a ANPEd, que nos apresenta o conceito e as práticas da educação inclusiva, reunindo as contribuições de pesquisadores brasileiros e de especialistas internacionais nesse campo, nos permitiu dar visibilidade a alguns trechos e discursos no intuito de destacar recorrências e singularidades quanto aos temas da inclusão, bem como pensar sobre os possíveis efeitos em relação às verdades impressas e disseminadas em tais documento. Sendo assim ao decorrer desta escrita analítica buscamos fazer um convite para pensar e tensionar como se dá a constituição do imperativo da inclusão que se ocupa em produzir tecnologias de governo capazes de condução das condutas na contemporaneidade.

\section{RÉFÉRENCES BIBLIOGRAPHIQUES}

AINSCOW, M.; Tornar a Educação Inclusiva: como esta tarefa deve ser conceituada?. In: IRELAND T.; BARREIROS D.; FÁVERO O.; FERREIRA W. (Orgs). Tornar a educação inclusiva. Brasília: UNESCO, p. 11-23, 2009.

FERREIRA, Júlio Romero, Financiamento da educação básica: o público e o privado na educação especial brasileira. In: IRELAND T.; BARREIROS D.; FÁVERO O.; FERREIRA W. (Orgs). Tornar a educação inclusiva. Brasília: UNESCO, p. 55-64, 2009.

FLEURI, Reinaldo Matias, Complexidade e interculturalidade: desafios emergentes para a formação de educadores em processos inclusivos. In: IRELAND T.; BARREIROS D.; FÁVERO O.; FERREIRA W. (Orgs). Tornar a educação inclusiva. Brasília: UNESCO, p. 65-88, 2009.

FOUCAULT, Michel. A hermenêutica do sujeito. São Paulo: Martins Fontes, 2006. .O sujeito e o poder. In: DREYFUS, Hubert; RABINOW, Paul. Michel Foucault, uma trajetória filosófica. Rio de Janeiro: Forense Universitária, 1995a. p. 231-249.

.A ordem do discurso. São Paulo: Editora Loyola, 2006.

HACKER, P.M.S. Wittgenstein:sobre a natureza humana. São Paulo: Editora Unesp, 2000.

MACHADO, Roseli Belmonte. A inclusão como rede: uma análise de práticas de professores de Educação Física na Contemporaneidade. 2016. p. 309. Tese (Doutorado em Educação), Programa de Pós-Graduação em Educação da Universidade Federal do Rio Grande do Sul, Porto Alegre, RS, 2016.

MENEZES, Eliana da Costa Pereira. A Maquinaria Escolar na Produção de Subjetividades para uma Sociedade Inclusiva. (Tese de Doutorado). Programa de Pós-Graduação em Educação/UNISINOS. São Leopoldo 2011.

POSSA, Leandra B. Formação em Educação Especial na UFSM: estratégias e modos de constituir-se professor. 2013. 239p. Tese (Doutorado). Universidade Federal de Santa Maria, Centro de Educação, Programa de Pós- Graduação em Educação, RS, 2013. 
SÁNCHEZ , P. A.; A Educação Inclusiva na Espanha In: IRELAND T.; BARREIROS D.; FÁVERO O.; FERREIRA W. (Orgs). Tornar a educação inclusiva. Brasília: UNESCO, p. 89-103, 2009.

VEIGA-NETO, Alfredo; LOPES, Maura Corcini. Inclusão e Governamentalidade. Educação \& Sociedade, Campinas, v. 28, n. 100, p. 947-964, out. 2007. 